\title{
Song Means: Analysing and Interpreting Recorded Popular Song
}

\author{
Allan F. Moore \\ Farnham and Burlington VT: Ashgate Publishing Limited, 2012. \\ ISBN: 978-1-4094-2864-0 (HB)
}

\author{
Melissa Avdeeff \\ Independent Researcher \\ melissa.avdeeff@gmail.com
}

Allan Moore opens Song Means: Analysing and Interpreting Recorded Popular Song by asking "what meanings can experiencing a song have and how does it create those meanings?" (1). Answering these questions is at the heart of Moore's text, through a discourse on how we can analyze and subjectively create meaningful relationships with popular music songs. Moore treats analysis and meaning as dichotomous discussions. Throughout Song Means, the role of the listener is acknowledged in the construction of meaning, which is guided by subjective experiences. The role of analysis is approached from a more formalist methodology, in an effort to survey the relationship between instruments, chord progressions, timbres, genre expectations and lyrics. Overall, Song Means provides what will, no doubt, become a seminal text within popular music studies. Moore has taken on the huge task of synthesizing, not only twenty years of his own academic writings, but also that of key figures within the field, including Richard Middleton (1990; 2000) Simon Frith (1983; 1998), and Philip Tagg (2000). While popular music studies can seem quite diffuse from a layman's perspective, Song Means is an attempt to bridge that gap and bring a much needed cohesive factor to the field.

In order to ascertain the how of song meaning, the first half of the book explores the mechanics of popular music song. In the introductory methodologies chapter, it is noted that Moore's approach, which primarily focuses on songs from the late 1950s through 1960 s, could theoretically be applied to any style and decade of popular song. I would have to question this, as the analysis seems to only centre on genres which lend themselves to transcription in Western notation. While sampling-based genres are mentioned briefly, how this methodology might be applied to more electronic based styles, such as EDM, or even rap music, is not explored. Song Means focuses on recorded music and, as such, is dependent on repeat listening, so it would be interesting to see if the methodology could be extended to live performances as they remain an integral aspect of music consumption. Even given these points, as a musicologist, I believe Moore's foundational methodology has merit and credibility for elucidating song meaning and interpretation across the genres. 
Chapters 2 through 5 offer a methodology for analysis in the form of: Shape, Form, Delivery and Style. Moore's approach should appeal to a wide range of readers, as he assumes a degree of prior musical knowledge, including the ability to read notation and understand chordal analysis, but not to the point of condescension for those with more specialist knowledge. The application of formalist analysis to popular music has faced much criticism, but Moore meets detractors head on by identifying the importance of establishing context before one can establish meaning. In his words, "In order to communicate to somebody else a particular part of our experience, we need to find a way of identifying that part, in the context of other parts" (51). Throughout the discussion on analysis, Moore upholds a value-neutral approach. While the majority of his examples originate from 50 s and 60 s rock genres, by not placing value judgments on the analysis, or interpretation of individual songs, Moore adheres to his goal of not creating a popular music canon. As an example, Bob Dylan and Girls Aloud are approached without comparisons to each other's perceived worth or contribution to the development of popular music.

This lack of value judgment becomes increasingly important as Moore moves into the meaning and interpretation chapters: Persona, Reference, Belonging and Synthesis (Chapters 7 through 10). In the chapter on Belonging, in particular, Moore tackles the incredibly loaded term, Authenticity, by treating it fairly, and without associating it with an inherent notion of value. Moore's discussion removes a lot of the rockist value perceptions of authenticity and, instead, places the power of the term back into the hands of the listener. As such, authenticity becomes genre-dependent, as well as listener-interpreted. For Moore, there is "not a single authenticity" (260) and, like all meanings, "it is ascribed, not inscribed" (Moore's emphasis, 266). The inscription of meaning is central to Moore's stance on interpretation. By shifting away from the extra-musical elements, Moore repositions his focus on the listener, as guided by their habitus, to borrow a sociological term. I question whether this might limit analysis to songs to which one already has meaningful engagement: even if a popular music canon does not unfold, would not a personal repertoire of songs, based on previous engagement, develop?

In order to make us aware of the role of the listener, Moore acknowledges his own subjectivity in Chapter 10 , by sharing his position on the autism spectrum disorder and how it informs his writing style. This declaration makes one re-evaluate their initial reading of the text because if Moore's own subjectivity could influence his writing style and process of analysis, then it reinforces the notion that our identity guides the meanings that we create with music.

The final Chapter, Questions, presents a list of questions, divided according to respective chapter, in order to guide an analysis and interpretation of any popular music song. Moore provides an excellent tool for university educators looking to present a straightforward methodology to their students, as it synthesizes and clarifies a lot of the concepts presented in Song Means, while also bringing a sense of cohesion to the book. I find it particularly effective that the questions are located within one chapter, rather than interspersed throughout the text.

Moore ends the main text of Song Means by asking the important questions: so what? Is listening not enough? It is noted that by looking deeper into a song, we "learn about ourselves" (286). Value, for Moore, lies not in which songs are "good" or "bad", but from what we personally acquire through the listening experience, as well as the relationships we develop through an interpretation that goes further than sounddeep. Defining popular music is a difficult enough task, but developing language to describe our interpretations is arguably more so. Moore has provided us with the tools, by recognizing that interpretations will differ widely. In his discussion of style, he eloquently describes the overall focus of Song Means: "consider a style to be like a constellation: it consists of individual stars and everyone can see the same stars, but how they draw the constellation will depend on their perspective" (120). 


\section{References}

Frith, S. -

1983. Sound Effects. London: Constable.

1998. Performing Rites. New York NY: Oxford University Press.

Middleton, R. -

1999. Studying Popular Music. Buckingham: Open University Press.

2000. Popular Music Analysis and Musicology: bridging the gap. In Richard Middleton Ed. Reading Pop. Oxford: Clarendon: 104-121.

Tagg, P. 2000 Analysing popular music: theory, method, and practice. In Richard Middleton Ed. Reading Pop. Oxford: Clarendon: 71-103. 